University of Nebraska - Lincoln

DigitalCommons@University of Nebraska - Lincoln

Faculty Publications: Department of Entomology

\title{
Light-Induced Variability in Development of Forensically Important Blow Fly Phormia regina (Diptera: Calliphoridae)
}

\author{
P. D. Nabity \\ University of Nebraska-Lincoln \\ Leon G. Higley \\ University of Nebraska-Lincoln, Ihigley1@unl.edu \\ Tiffany Heng-Moss \\ University of Nebraska-Lincoln, thengmoss2@unl.edu
}

Follow this and additional works at: https://digitalcommons.unl.edu/entomologyfacpub

Part of the Entomology Commons

Nabity, P. D.; Higley, Leon G.; and Heng-Moss, Tiffany, "Light-Induced Variability in Development of Forensically Important Blow Fly Phormia regina (Diptera: Calliphoridae)" (2007). Faculty Publications: Department of Entomology. 276.

https://digitalcommons.unl.edu/entomologyfacpub/276

This Article is brought to you for free and open access by the Entomology, Department of at DigitalCommons@University of Nebraska - Lincoln. It has been accepted for inclusion in Faculty Publications: Department of Entomology by an authorized administrator of DigitalCommons@University of Nebraska - Lincoln. 


\title{
Light-Induced Variability in Development of Forensically Important Blow Fly Phormia regina (Diptera: Calliphoridae)
}

\author{
P. D. NABITY, ${ }^{1}$ L. G. HIGLEY, ${ }^{2,3}$ AND T. M. HENG-MOSS ${ }^{2}$
}

J. Med. Entomol. 44(2): 351-358 (2007)

\begin{abstract}
The use of the postmortem interval (PMI) in practical applications of forensic entomology is based upon developmental data of blow flies (Diptera: Calliphoridae) generated under controlled environmental conditions. Careful review of the published forensic entomology data sets showed that experimental (environmental) parameters differed between studies. Despite the differences in study design, there are no empirical data on the effect of photoperiod on blow fly development; yet, photoperiod has been shown to alter some insect development and behavior among noncalliphorids. Consequently, will differences in photoperiod alter the developmental times of calliphorids, and thereby alter PMI estimates? To answer this question, we used a replicated design with precise temperature measurement to examine the effects of photoperiod on the forensically important blow fly Phormia regina (Meigen). We concluded that inaccurate temperature recordings by using set-chamber temperatures over rearing-container temperatures would have overshadowed any affect light had on development. Second, constant light increased variation in overall adult developmental time and significantly delayed development compared with cyclic light. Finally, not accounting for delayed development induced by photoperiod underestimated the initial empirical estimate of the PMI. These sources of variation need to be included in forensic estimates because this variation can compromise predictions of PMI based upon current data sets. Without pinpointing optimal photoperiods with which to test development, we must assume that potentially large sources of variability exist within current estimates of the PMI.
\end{abstract}

KEY WORDS forensic entomology, PMI, photoperiod

Forensic entomology is used in most criminal cases by comparing temperature-constrained development of calliphorid flies on human remains to determine a specific time interval between discovery of the body and when insect colonization occurred (typically shortly after death). This postmortem interval (PMI) is constructed using insect development data and degree-day analysis. Although there is variability in calculated degree-days between data sets published on the same species, comparisons of conspecific data show the temperature-development time relationship is similar (Clarkson et al. 2004, Huntington 2005, Nabity et al. 2006). Through degree-day analysis based on existing developmental data and best available scene temperatures, an initial empirical estimate of the PMI is made. After an empirical time frame is determined, the time frame estimate is amended to address scene-specific context and sources of variability (e.g., weather phenomena, insect accessibility to body, and so on) (Catts and Haskell 1990, Lord et al. 1994, Anderson 1997, Byrd and Castner 2001). Although scene-specific variability may be estimated

\footnotetext{
${ }^{1}$ Department of Plant Biology, University of Illinois, 265 Morrill Hall, Urbana, IL 61801.

${ }^{2}$ Department of Entomology, University of Nebraska-Lincoln, 202 Plant Industry, Lincoln, NE 68583-0816.

${ }^{3}$ Corresponding author, e-mail: lhigley1@unl.edu.
}

and more or less depends on case histories as opposed to published research articles, variability occurring within the initial empirical estimate of the PMI has not been discussed (Nabity et al. 2006). This is largely from a lack of attention to flaws in design (e.g., pseudoreplication and inaccurate temperature measurement) of temperature-controlled larval rearing (Nabity et al. 2006). Several potential sources of error have previously been addressed: pupal handling (Ash and Greenberg 1975, Anderson 2000), maggot mass temperatures (Greenberg 1991), larval substrate (Clark et al. 2006, Day and Wallman 2006), and constant versus fluctuating temperatures (Byrd and Allen 2001, Clarkson et al. 2004). However, there are many more areas of concern, such as experimental design/units, temperature measurement, photoperiod, and relative humidity. Recently, we have examined sources of variability from problems in experimental design and failures to meet assumptions required in calculating degree-days (Nabity et al. 2006).

Most measures of development by forensically important flies [e.g., Calliphora vicina Robineau-Desvoidy, Cochliomyia macellaria (F.), Lucilia sericata (Meigen), and Phormia regina (Meigen) ] reared under controlled temperatures were generated under a photoperiod of 24:0 (L:D) h (Greenberg 1991, Byrd and Butler 1996, 1997, 1998; Byrd and Allen 2001; 
Huntington 2005; Nabity et al. 2006). Within these studies, some only used a photoperiod of 24:0 (L:D) h for one constant temperature (Byrd and Butler 1996, 1997, 1998) and used 12:12 (L:D) h for the remaining fluctuating temperatures. Still, other studies used constant darkness (Grassberger and Reiter 2002a) or did not report the experimental photoperiod (Greenberg and Tantawi 1993; Anderson 2000; Grassberger and Reiter 2001, 2002b; Grassberger et al. 2003; Clarkson et al. 2004).

Many investigators have justified the use of specific photoperiods in developmental studies to avoid the phototaxic stage transition phenomenon known as emergence gating (Dallwitz 1984, Greenberg 1991, Davies and Ratcliffe 1994, Byrd and Allen 2001). Emergence gating is defined as a phenomenon where stage transitions (e.g., adults emerging from pupae) occur in synch with environmental cycles (in this case a diurnal photoperiod or onset of a light cycle) (Pittendrigh 1967). Subsequently, Byrd and Allen (2001) used a photoperiod of 12:12 (L:D) h on developing larvae, but they switched to a photoperiod of 24:0 (L:D) h for pupal development to avoid emergence gating, whereas Greenberg (1991) and Davies and Ratcliffe (1994) used the gating phenomenon as the basis for selecting a photoperiod of 24:0 (L:D) h. If light does not significantly influence development, photoperiod should not matter. Alternatively, if photoperiod alters development through emergence gating or other processes, the role of photoperiod should be considered to ensure developmental data on forensically important species are valid in the field.

To date, there have been few evaluations on the influence of light on the development of forensically important fly species. Recent studies evaluated temperature-photoperiod affects on diapause of calliphorids (McWatters and Saunders 1998, Tachibana and Numata 2004), but because of the interaction between light and temperature, direct light-induced effects on physiology were not measured. In a study on the larval growth rates of the sarcophagid Sarcophaga argyrostoma (Robineau-Desvoidy), Saunders (1972) showed light altered the physiological growth rate and total length of the developing instar. Although S. argyrostoma is a sarcophagid, it is considered a forensic indicator species (Byrd and Butler 1997, Byrd and Castner 2001). Another related fly (same suborder: Brachycera), Drosophila melanogaster (Meigen), has been thoroughly examined in its physiological response to photoperiod (Harker 1964, 1965; Skopik and Pittendrigh 1967; Pittendrigh and Skopik 1970) and showed greater variability in stage transition under constant light (Skopik and Pittendrigh 1967, Pittendrigh and Skopik 1970).

Among insects in general, physiological variability has been induced through manipulations of experimental photoperiods. Cyclic light has been shown to increase cold tolerance in Spodoptera exigua (Hübner) compared with constant or no light conditions (Kim and Song 2000). Photoperiod also has been shown to alter egg production in $S$. nonagrioides (Fantinou et al. 2004) and to induce diapause in nu- merous insects (Roach and Adkisson 1970, McWatters and Saunders 1998, Fantinou et al. 2003, Tachibana and Numata 2004). More significantly, however, photoperiod has been shown to alter developmental times (and rates) of insects (e.g., Sarcophagidae, Saunders 1972; Pentatomiidae, Nakamura 2003; Chrysomelidae, Piesik 2006; and Coccinellidae, Omkar and Pathak 2006)

Although there are no direct evaluations of the effect of light on forensically important calliphorid fly species, observations have been noted. Grassberger and Reiter (2001, 2002a,b) and Grassberger et al. (2003) found pupation occurred on top of their rearing media under "low" (unspecified) light conditions but not under high light, indicating phototaxic responses. Davies and Ratcliffe (1994) noted larval exodus from rearing substrate readily occurred under an administered scotophase (darkness during photoperiod), whereas Kocarek (2001) observed field larval emigration of Lucilia caesar (L.) and Calliphora vomitoria (L.) occurred only at night. Fly larvae are known to be negatively phototaxic, moving away from light, and adult flies typically do not oviposit and fail to seek hosts (carrion) at night (Tessmer et al. 1995, Spencer 2002). Some studies have contested this last point regarding nocturnal oviposition (Greenberg 1990, Singh and Bharti 2001); however, one study had an experimental constraint and placed the bait at ground level near bushes, which may have confounded the conclusion that flies seek hosts at night. Still, Singh and Bharti (2001) showed oviposition could occur (in five of 14 tests) at night. Because oviposition did not occur every night as was the case with tests for oviposition during the day, the tests indicated light played some role in host seeking or oviposition behavior. Thus, phototaxic responses are known to alter the behavior during development and at the onset of development (oviposition). Consequently, our goal was to test the effects of constant and cyclic lighting within an environmental growth chamber on overall developmental time. This issue of photoperiod is of interest to the practical application of forensic entomology when determining the PMI, which is dependent upon accurate developmental data and assessment of variability.

\section{Materials and Methods}

We examined fly development under different photoperiods in two experiments to determine whether light altered development. We conducted each experiment at one of two temperatures $\left(25\right.$ and $20^{\circ} \mathrm{C}$ ) and used a completely randomized treatment assignment of light and temperature to chambers for both experiments. For each experiment, we applied two light treatments (12:12 and 24:0 [L:D] h) to our experimental units (environmental growth chambers). We used four replications (chambers) per light treatment with three rearing containers (subsamples) per chamber for a total of 12 subsamples per treatment per experiment. We increased the number of subsamples to 15 per treatment for the $20^{\circ} \mathrm{C}$ experiment because we had additional fly eggs and chambers. Also previ- 
ous experiments were subject to some chamber malfunctions (as indicated by internal thermocouples and data loggers); therefore, they were removed from the data set.

Flies were collected from the University of $\mathrm{Ne}$ braska East Campus in Lancaster County, NE $\left(40^{\circ} 85^{\prime}\right.$, $96^{\circ} 75^{\prime}$ ) by using traps baited with liver. P. regina were identified, separated, and placed in fine wire mesh cages ( 30 by 30 by $30-\mathrm{cm}$ cubes) in laboratory growth chambers (models E-30B, I-35L, LLVL, and VLX, Percival Scientific, Perry, IA). Colony temperatures were set from 20 to $25^{\circ} \mathrm{C}$ and assigned a photoperiod of $24: 0$ (L:D) h. Relative humidity varied with season (50$70 \%)$. Eggs were collected after oviposition on liver. We used egg masses of approximately equal size and $<3 \mathrm{~h}$ old for experiments. Although egg masses differed in absolute number of eggs, we added liver substrate across all subsamples homogenously, and ad libitum to reduce competition. Flies from the seventh and 10th generations were used for the 25 and $20^{\circ} \mathrm{C}$ temperature experiments, respectively, with emerged flies used to restock the colonies.

Larvae developed on beef liver enclosed in foil pouches in 3.55-liter containers lined with mediumgrade vermiculite. All containers were vented to allow for gas exchange. We measured pupal and adult stage transition times using the fastest developmental time (typically $\leq 10 \%$ of the population). We checked all chambers at 12 -h intervals and recorded fly emergence at each time frame.

Thermocouples (TMCx-HD, with -40 to $50^{\circ} \mathrm{C}$ range $\pm 0.5^{\circ} \mathrm{C}$ accuracy at $20^{\circ} \mathrm{C}$, and $0.41^{\circ} \mathrm{C}$ resolution) from a Hobo H8 Outdoor/Industrial 4-Channel External Logger (Onset Computer Corp., Pocasset, MA) were used to record internal chamber and rearing container temperatures. One thermocouple was placed in each rearing container. Thus, three thermocouples recorded temperatures in different rearing containers, and one thermocouple recorded internal chamber temperature. For both temperature studies, thermocouples placed within rearing containers measured overall rearing container temperature to the nearest $0.1^{\circ} \mathrm{C}$ and every $15 \mathrm{~min}$ to account for any metabolic heat generated.

The developmental minima, maxima, and thermal constants were determined to ensure that degree-day models were based solely on the linear portion of the developmental curve. Commonly, these values are determined by regressing development time ${ }^{-1}$ versus temperature and by using the intercept of this regression as a base temperature for calculating the thermal constant. Because the inverse of development time skews the variance structure, this approach underestimates low temperature curvilinearity (and overestimates high temperature curvilinearity) and underestimates the slope of the actual linear portion of the developmental curve. Consequently, we used a multiple step procedure to avoid these problems.

First, we identified the linear portion of the development curve by iteratively checking for nonlinearity in the lower and upper portions of the developmental curve. Specifically, for regressions of development time in days versus temperature and of $1 / \mathrm{d}$ versus temperature, we 1) used a runs test (a statistical measure of unidirectional error, or nonrandomness) to identify significant nonlinearity in the regression (GraphPad Prism four software (GraphPad Software Inc., San Diego, CA), 2) examined $R^{2}$ values and patterns of residuals from regressions (GraphPad Software Inc.), and 3) looked at $95 \%$ prediction bands (indicating where $95 \%$ of data points fall between) for observed data points in the $1 / \mathrm{d}$ versus temperature regression. We used $95 \%$ prediction bands as opposed to $95 \%$ confidence intervals, which result in many points outside the bands because the $95 \%$ confidence interval is a measure of the true mean or relationship, not a prediction of where points should be. Based on these criteria, we sequentially eliminated low and upper temperature points until the runs test was nonsignificant, the $R^{2}$ showed no improvement, residuals showed a random distribution, and experimental points were within $95 \%$ prediction bands of the regression.

Second, we determined the developmental minimum from the $\mathrm{x}$-intercept from a linear regression; once the appropriate temperature range was established, we regressed 1/developmental time versus temperature to determine the appropriate developmental minimum.

Third, we calculated the thermal constant (accumulated degree-days) for the biological period of interest (here, development from egg to adult). For each treatment temperature, this was (temperature minimum)*development time.

Fourth, we confirmed that the calculated thermal constants are independent of temperature. The slope of the linear regression of thermal constants versus temperature was tested to determine whether it was significantly different from zero.

Finally, we determined the thermal constant either by slope of the thermal constant versus temperature regression or the mean of the thermal constant across measured temperatures. These values should be approximately equal, and there is no a priori reason to choose one over the other. However, because most literature values of thermal constants are based on means, we also used the mean for comparison. Because temperature recordings were made every 15 min, we calculated daily degree-days as the sum of these 15-min intervals over a day.

\section{Data Analysis}

Duration of $P$. regina development within median temperatures $\left(20-30^{\circ} \mathrm{C}\right)$ follow a near linear relationship (Nabity 2005). Therefore, we used linear regression to analyze our data because chamber internal temperatures varied and subsequently affected rearing-container temperatures. Differences between light treatments were determined by analyzing residuals (error from a regression line) and differences in developmental rate over the same temperatures. We compared treatments at recorded stage transition times (pupation and emergence) by using an analysis 
Table 1. Raw data for $P$. regina development under different light treatments from 2004

\begin{tabular}{|c|c|c|c|c|c|c|c|c|c|c|c|}
\hline \multicolumn{6}{|c|}{$25^{\circ} \mathrm{C}$ set-chamber temp } & \multicolumn{6}{|c|}{$20^{\circ} \mathrm{C}$ set-chamber temp } \\
\hline \multicolumn{3}{|c|}{ 12:12 (L:D) h } & \multicolumn{3}{|c|}{$24: 0(\mathrm{~L}: \mathrm{D}) \mathrm{h}$} & \multicolumn{3}{|c|}{ 12:12 (L:D) h } & \multicolumn{3}{|c|}{$24: 0(\mathrm{~L}: \mathrm{D}) \mathrm{h}$} \\
\hline Cont. ${ }^{\circ} \mathrm{C}$ & Adev & Pdev & Cont. ${ }^{\circ} \mathrm{C}$ & Adev & Pdev & Cont. ${ }^{\circ} \mathrm{C}$ & Adev & Pdev & Cont. ${ }^{\circ} \mathrm{C}$ & Adev & Pdev \\
\hline 21.5 & 17.4 & 10.9 & 23.2 & 16.9 & 8.9 & 18.9 & 21.8 & 11.8 & $17.5^{a}$ & 24.8 & 13.3 \\
\hline 21.5 & 16.4 & $7.9^{b}$ & 23.3 & 15.6 & 8.6 & 20.2 & 19.3 & 10.8 & 19.5 & 21.8 & 12.8 \\
\hline 21.5 & 17.0 & 10.0 & 23.4 & 14.9 & 8.4 & 20.2 & 18.8 & 10.3 & 19.5 & 18.8 & 11.3 \\
\hline 21.6 & 16.9 & 8.9 & 23.4 & 17.0 & 11.0 & 20.5 & 19.3 & 11.3 & 19.5 & 23.3 & 14.8 \\
\hline 22.6 & 16.1 & 9.6 & 23.4 & 15.4 & 8.9 & 21.2 & $15.3^{b}$ & 9.8 & 19.9 & 21.3 & 12.8 \\
\hline 22.7 & 16.1 & 9.6 & 24.5 & 13.9 & 8.4 & 21.3 & 17.3 & 9.8 & 21.4 & 16.8 & 10.3 \\
\hline 22.9 & 16.1 & 9.1 & 24.5 & 14.9 & 8.9 & 22.1 & 15.8 & 8.8 & 21.5 & 15.8 & 10.8 \\
\hline 22.9 & 15.1 & 8.0 & 24.7 & 14.9 & 8.4 & 22.2 & 15.8 & 8.3 & 21.8 & 19.3 & 11.8 \\
\hline 23.2 & 15.1 & 9.1 & 25.0 & 14.6 & 9.1 & 23.6 & 13.8 & 7.8 & 22.7 & 15.3 & 9.8 \\
\hline 23.2 & 15.1 & 9.1 & $25.7^{a}$ & 14.6 & 9.1 & 23.9 & 13.8 & 7.8 & & & \\
\hline 23.7 & 15.1 & 9.1 & $25.9^{a}$ & 13.0 & 8.0 & & & & & & \\
\hline 24.1 & 14.0 & 8.0 & $26.0^{a}$ & 13.6 & 8.0 & & & & & & \\
\hline 24.3 & 13.9 & 7.9 & $26.3^{a}$ & 13.0 & 7.5 & & & & & & \\
\hline 24.4 & 12.9 & 7.4 & $27.8^{a}$ & 13.0 & 8.0 & & & & & & \\
\hline 24.6 & 14.9 & 8.9 & $28.0^{a}$ & 13.6 & 8.6 & & & & & & \\
\hline
\end{tabular}

Each study was designed for a determined set-chamber temperature reflecting what the environmental growth was set at; however, deviations by the environmental chambers resulted in constant rearing-container temperatures $\left(\max \mathrm{SE} \pm 0.3^{\circ} \mathrm{C}\right)$ different from set-chamber temperatures. Adev, developmental time (d) from egg to adult emergence; Pdev, developmental time (d) from egg to pupation; Cont., rearingcontainer temperature $\left({ }^{\circ} \mathrm{C}\right)$

${ }^{a}$ Data are not included in the analyses because temperatures are out of range for comparison $\left(\geq 1^{\circ} \mathrm{C}\right.$ from closest point).

${ }^{b}$ Data were excluded from analyses because they fell outside the $95 \%$ prediction band.

of covariance (ANCOVA) at a significance level of $P \leq$ 0.05 (PROC MIXED, SAS Institute 2002) with container temperature as a covariate, because rearingcontainer temperatures can differ substantially from set-chamber temperatures (Huntington 2005, Nabity 2005)

We conducted a meta-analysis (a statistical analysis integrating the results of multiple studies (Hedges and Olkin 1985) to determine how the current study compared with a previous study testing development only under constant light (Nabity et al. 2006). For both studies, methods were the same. The meta-analysis was conducted using an ANCOVA at a significance level of $P \leq 0.05$ (PROC MIXED, SAS Institute 2002). We transformed our data to reflect developmental rate (inverse developmental time or days ${ }^{-1}$ ) as is the practice for degree-day and standard forensic analyses. We then regressed the data against container temperature to determine slope and $\mathrm{x}$-intercepts.

\section{Results}

P. regina developed at different rates under each photoperiod tested (Table 1 ). In the $20^{\circ} \mathrm{C}$ test, developmental time to pupation and pupation duration differed between treatments $(P=0.031$ and 0.0155$)$, although time to adult emergence did not differ $(P=$ 0.37 ). In the $25^{\circ} \mathrm{C}$ test, developmental time to adult emergence differed between treatments $(P=0.0146)$, although pupal developmental time and pupation duration did not differ $(P=0.10$ and 0.18$)$. Developmental time from egg to pupation and egg to adult emergence occurred faster under cyclic light than under constant light; therefore, we combined both tests to show development over a similar range of temperatures (Fig. 1).

In our comparison across a similar range of temperatures, developmental time to pupation and adult emergence both occurred faster under cyclic light $(P=0.001$ and 0.0046$)$, but pupation duration did not differ between light treatments $(P=0.54)$. Under a meta-analysis comparing constant light developmental data from this study to a previous study testing development under constant light (Nabity et al. 2006), all developmental times of the current study (to pupation, to emergence, and duration of pupation) did not differ between studies $(P>0.21)$. Conversely, developmental time to pupation and pupation duration under cyclic light occurred faster $(P=0.0088$ and 0.047 ) in the current study than in the previous study at constant light across a similar range of temperatures $\left(18.4-25.5^{\circ} \mathrm{C}\right)$. Developmental time to adult emer-

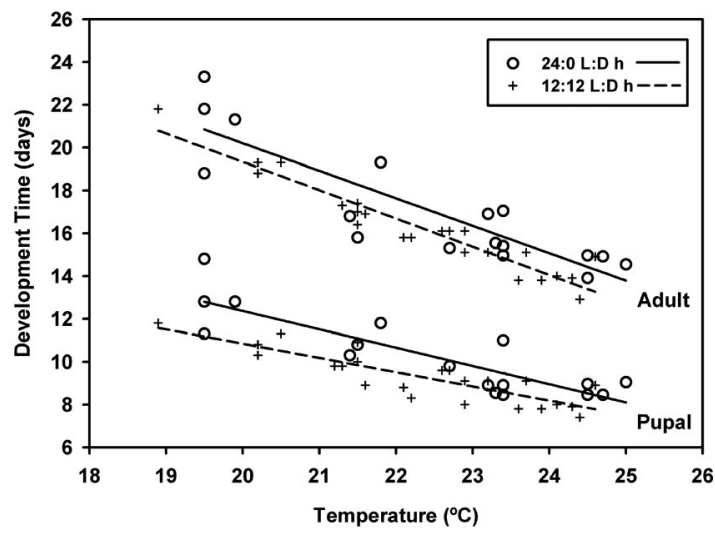

Fig. 1. Linear regression of combined tests of photoperiod for developmental time from egg to adult emergence (A) and egg to pupation (P) by using rearing container temperatures. Formulae and correlation for each treatment are as follows: $12: 12, \mathrm{~A}=-1.321 \mathrm{x}+45.75, R^{2}=0.91 ; 24: 0, \mathrm{~A}=$ $-1.283 \mathrm{x}+45.87, R^{2}=0.77 ; 12: 12, P=-0.665 \mathrm{x}+24.15, R^{2}=$ 0.73 ; and $24: 0, P=-0.853 \mathrm{x}+29.43, R^{2}=0.75$. 


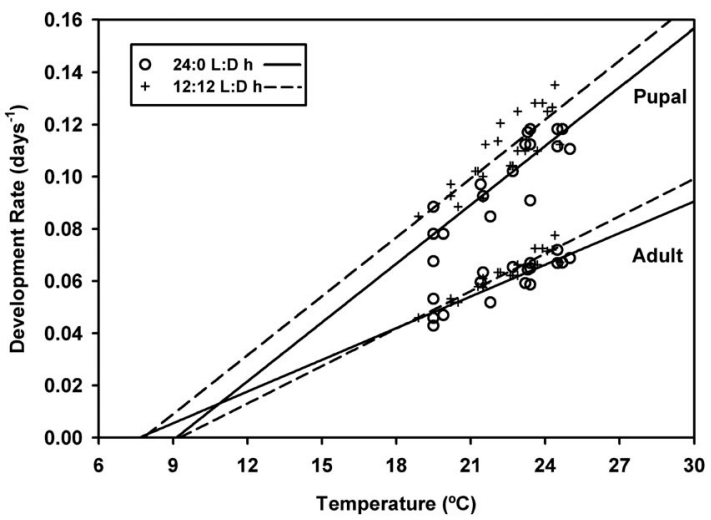

Fig. 2. Linear regression of combined tests of photoperiod for developmental rate from egg to adult emergence (A) and egg to pupation $(\mathrm{P})$ by using rearing container temperatures. Formulae and correlation for each treatment are as follows: $12: 12, \mathrm{~A}=0.0048 \mathrm{x}-0.0444, R^{2}=0.90 ; 24: 0, \mathrm{~A}=$ $0.0040 \mathrm{x}-0.0310, R^{2}=0.79 ; 12: 12, P=0.0075 \mathrm{x}-0.0587, R^{2}=$ 0.69 ; and $24: 0, P=0.0075 \mathrm{x}-0.0686, R^{2}=0.76$. Calculated $\mathrm{x}$-intercepts are $12: 12, \mathrm{~A}=9.3 ; 24: 0, \mathrm{~A}=7.7 ; 12: 12, P=7.8$; and $24: 0, P=9.1$

gence did not differ $(P=0.12)$. In comparisons of each temperature treatment $\left(20\right.$ and $\left.25^{\circ} \mathrm{C}\right)$ to the previous study, developmental time to pupation and pupation duration were significantly faster at $20^{\circ} \mathrm{C}(P=0.007)$, whereas developmental times to pupation and adult emergence were faster at $25^{\circ} \mathrm{C}(P=0.02$ and 0.006$)$. The remaining measures of time (developmental time to emergence at $20^{\circ} \mathrm{C}$ and pupation duration at $25^{\circ} \mathrm{C}$ ) did not differ from one another $(P>0.17)$ (for raw data for both studies, see Nabity 2005).

Developmental rates under cyclic light were higher than under constant light across temperatures and generated different minimum thresholds (x-intercepts) through linear regression (Fig. 2). The differences between regression parameters led to differences in accumulated degree-days (Fig. 3). We calculated accumulated degree-days (ADD) for each treatment for time from egg to pupation $\left({ }^{\mathrm{e}-\mathrm{p}} \mathrm{ADD}_{\mathrm{Tb}}\right)$ and egg to adult emergence $\left({ }^{\mathrm{e}-\mathrm{a}} \mathrm{ADD} \mathrm{Db}_{\mathrm{Tb}}\right)$, by using $\mathrm{x}$-intercept developmental minima determined from these experiments. (The minima used here are higher than the base temperatures from the entire linear range of temperatures where development occurs [Nabity et al. 2006], because only two set chamber temperatures within the linear range were examined here.) Although there was no difference between treatments in ADD to pupation (cyclic ${ }^{\mathrm{e}-\mathrm{p}} \mathrm{ADD}_{7.8}=$ 134 , constant $\left.{ }^{\mathrm{e}-\mathrm{p}} \mathrm{ADD}_{91}=134\right)$, there was a large difference in ADD to adult emergence (cyclic $\left.{ }^{\mathrm{e}-\mathrm{a}} \mathrm{ADD}_{9.3}=209,{ }^{\mathrm{e}-\mathrm{a}} \mathrm{ADD}_{7.7}=247\right)$.

\section{Discussion}

Variation in temperatures can occur cyclically, in diurnal patterns associated with mechanical function or light settings. In a similar study testing development of $P$. regina, a photoperiod effect was observed where

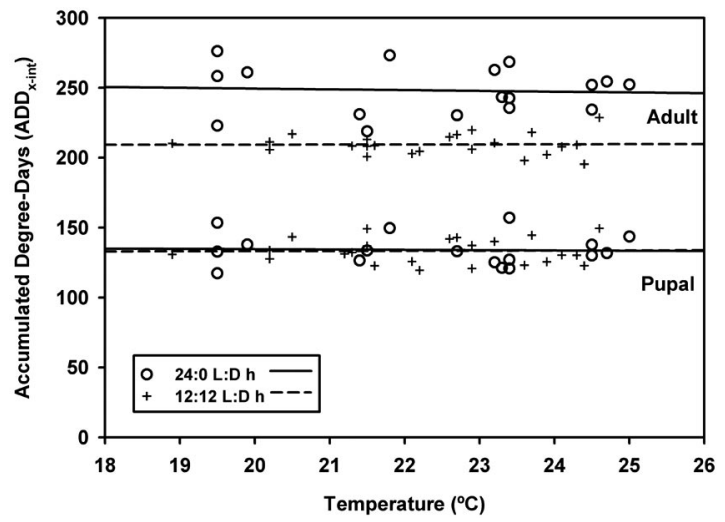

Fig. 3. Linear regression of combined tests of photoperiod for accumulated degree-days from egg to adult emergence $(\mathrm{A})$ and egg to pupation $(\mathrm{P})$ by using rearing container temperatures. Formulae and correlation for each treatment are as follows: $12: 12, \mathrm{~A}=-0.062 \mathrm{x}+208, R^{2}=0.0002 ; 24: 0$, $\mathrm{A}=-0.549 \mathrm{x}+260, R^{2}=0.0036 ; 12: 12, P=-0.012 \mathrm{x}+131$ $R^{2}=0.0004 ;$ and 24:0, $P=-0.213 \mathrm{x}+139, R^{2}=0.0013$. Calculated thermal constants $(\mathrm{K}=1 / \mathrm{b})$ are $12: 12, \mathrm{~A}=209$; 24:0, $\mathrm{A}=247 ; 12: 12, P=133$; and 24:0, $P=133$. Averaged thermal constants are 12:12, $\mathrm{A}=209 ; 24: 0, \mathrm{~A}=247 ; 12: 12, P=$ 134 ; and $24: 0, P=134$

a $3.0^{\circ} \mathrm{C}$ difference between set-chamber temperature and internal chamber temperature (as recorded by thermocouples) was noted when lights were off compared with when lights were on (see Nabity 2005). Additionally, one chamber showed deviance between actual chamber temperature and temperature experienced by larvae within experimental container by as much as $3.7^{\circ} \mathrm{C}$ for consecutive 15 -min intervals during lighted time periods only. Because three different chambers showed an average gradient of $1-1.5^{\circ} \mathrm{C}$ between dark and light photoperiods, this gradient implies that chambers may be creating variability that can influence the development of the larvae and the credibility of degree-day models based on chamber temperatures. These chambers showed this diurnal occurrence randomly with no dependence on larval number, time of year of experiment, temperature, or chamber used. The same chambers run under constant lighting for later temperature trials showed no cyclical variation.

In this study, we observed deviation from set temperatures associated with lighting across chambers. At $25^{\circ} \mathrm{C}$, all rearing containers within chambers assigned to a photoperiod of 12:12 (L:D) h reported lower temperatures than the set temperature, whereas at $20^{\circ} \mathrm{C}$ all containers but one under the same treatment reported higher temperatures than the set-chamber temperature. Although the $25^{\circ} \mathrm{C}$ trial occurred November to December and the $20^{\circ} \mathrm{C}$ trial occurred June to July, this one-sided variation was not a function of ambient conditions, because the same pattern was not evident in the constant lighting treatment occurring at the same times of the year. In chambers assigned to 24:0 (L:D) h, rearing-container temperatures deviated randomly from set-chamber temperatures, indicating 
the observed deviation was mechanical in origin. This trend happened across chambers without regard for model type (models E-30B, I-35L, LLVL, and VLX, Percival Scientific Inc.). Therefore, all previous data on forensically important species may be more variable when proper temperature measures (thermocouples with data loggers) were not used, and future growth chamber studies should use reliable methods for recording temperatures actually experienced by developing insects to avoid possible misrepresentation.

Although chambers were set at equal temperatures, mechanical and environmental factors created dissimilar environments across chambers and even rearing containers. Without accurately representing larval developmental temperatures with thermocouples in rearing containers, we would not have been able to illustrate the significant effect light has on development. Cyclic lighting increased larval development as measured by faster times to pupation and to adult emergence. Our results indicated that developmental times from egg to pupation and pupation duration were faster under cyclic light around $20^{\circ} \mathrm{C}(18.9$ $23.9^{\circ} \mathrm{C}$ ) but did not differ from development around $25^{\circ} \mathrm{C}\left(21.5-25.0^{\circ} \mathrm{C}\right)$. But we did see that developmental times from egg to adult and egg to pupation were faster under cyclic lighting for both temperatures. Because insects spent more time developing under cyclic lighting at cooler temperatures, the effect on development seemed more pronounced. Although each experiment was conducted with a different fly generation $\left(25^{\circ} \mathrm{C}\right.$, seventh; $20^{\circ} \mathrm{C}, 10 \mathrm{th}$ ) any influence of fly generation on the results would have been equally shared across treatments.

Our results indicate that larval development of $P$. regina may be significantly affected by photoperiod. Previous studies alluded to gating as an influence on emerging flies where adult activity seemed strongly correlated with the onset of dawn (Dallwitz 1984, Greenberg 1991). If true, pupal duration should increase under constant darkness reflecting a behavioral pause until a specific stimulus occurs. Similarly, emergence should be more variable when developing under constant light because of lack of a stimulus (e.g., periods without light) (Skopik and Pittendrigh 1967, Pittendrigh and Skopik 1970). We expected stage transitions to be correlated strongly with light/ dark cycles. In contrast, across the temperatures tested, our data showed both larval and pupal development were more affected by light than pupation duration and that stage transitions did not strongly correlate to the onset of photophase. If development did correlate to photophase, we would expect a pattern where stage transition times occurred in groupings separated by $24-\mathrm{h}$ time intervals. Because no pattern was evident, gating may not constrain $P$. regina development. Instead, photoperiod may be interacting with the circadian rhythmicity of the fly to influence physiology (Schwartz 2004).

The increase in developmental time of $P$. regina under cyclic light is more important than the issue of gating. Our data showed a trend where developmental time decreased under cyclic lighting with decreasing temperature, i.e., cyclic light regression slope $<$ constant light regression slope. This suggests lower temperatures are acting in concert with light to alter physiological responses. Previous studies indicated light affected diapause in two other calliphorid fly species: Lucilia sericata (Meigen) and Calliphora vicina Robineau-Desvoidy (McWatters and Saunders 1998, Tachibana and Numata 2004). In both studies, maternal environmental conditions were shown to alter progeny incidence and duration of diapause. Would rearing a colony at 24:0 (L:D) h influence the outcome of a test of photoperiod? Because we know constant light increases the window or gate of emergence (Skopik and Pittendrigh 1967), we would expect differences between constant and cyclic light treatments to be diminished if a maternal light effect were present. Instead, we detected significant differences between treatments signifying that perhaps the effect is more significant than originally hypothesized. If light-triggered stimuli cause developmental rate to slow under constant light as seen in this study, then developmental rates determined from other studies on P. regina (Greenberg 1991, Anderson 2000), and of other forensically important species where constant light was used, are too slow. Consequently, tests on development under different naturally occurring (seasonal) light regimes are necessary to pinpoint the optimum photoperiod where development occurs the fastest.

Because developmental time has a direct bearing on determining the postmortem interval, previously calculated PMIs (already accepted as evidence in some legal cases) may be more variable. Wider PMIs already assume variability and therefore may not change when adjusted for light effects, but narrower PMIs may be misrepresentative. As presented in Fig. 3, there is a large difference in ADD to adult emergence between light treatments. If we assume 247 ADD are expected (based upon constant light), then not accounting for photoperiod affects on development could underestimate total ADD by as much as $15 \%$.

Early studies (Greenberg 1991, Davies and Ratcliffe 1994) called for scrutiny when conducting experiments with fly larvae because of notable maggot mass temperatures. Metabolically driven increases in temperature have since been accounted for by keeping the substrate proportionally larger than the number of larvae. Using thermocouples also accounts for increases in larval temperatures, perhaps more effectively, by detecting any deviation in substrate temperature. More importantly though, thermocouples account for within-chamber temperature deviations not detected by routine half-day thermometer viewings or chamber resistors. Without the use of thermocouples, within chamber variation would be incorporated into temperatures used in degree-day analyses. Based on our results it is reasonable to assume other developmental data are inaccurate. Until we investigate and uncover the optimum photoperiod for development and conduct our experiments to generate accurate temperature data, we must assume large 
sources of variability exist within estimates of the post mortem interval.

\section{Acknowledgments}

We thank S. M. Louda and S. M. Spomer for constructive discussions and editorial remarks, and all those who helped monitor fly development and colonies, especially T. R. Brosius, L. D. Franzen, A. Gutsche, T. E. Huntington, and S. E. Svehla. This work was supported by the Nebraska Agricultural Experiment Station (Projects NEB-17-078 and NEB17-080) and by awards to P.D.N. from the University of Nebraska Pepsi Endowment and Program of Excellence Funds for Undergraduate and Creative Activities and Research Experiences and from an Undergraduate Honors Grant from the Agricultural Research Division, UN-L. This is paper 15102 of the journal series of the University of $\mathrm{Ne}$ braska Agricultural Research Division.

\section{References Cited}

Anderson, G. S. 1997. The use of insects to determine time of decapitation: a case-study from British Columbia. J. Forensic Sci. 42: 947-950.

Anderson, G. S. 2000. Minimum and maximum development rate of some forensically important Calliphoridae (Diptera). J. Forensic Sci. 45: 824-832.

Ash, N., and B. Greenberg. 1975. Developmental temperature responses of the sibling species Phaenicia sericata and Phaenicia pallescens. Ann. Entomol. Soc. Am. 68: 197-200.

Byrd, J. H., and J. C. Allen. 2001. The development of the black blow fly, Phormia regina (Meigen). Forensic Sci. Int. 120: $79-88$.

Byrd, J. H., and J. F. Butler. 1996. Effects of temperature on Cochliomyia macellaria (Diptera: Calliphoridae) development. J. Med. Entomol. 33: 901-905.

Byrd, J. H., and J. F. Butler. 1997. Effects of temperature on Sarcophaga haemorrhoidalis (Diptera: Sarcophagidae) development. J. Med. Entomol. 34: 694-698.

Byrd, J. H., and J. F. Butler. 1998. Effects of temperature on Chrysomya rufifacies (Diptera: Calliphoridae) development. J. Med. Entomol. 35: 353-358.

Byrd J. H., and J. L. Castner. 2001. Insects of forensic importance, pp 43-79. In J. H. Byrd and J. L. Castner [eds.], Forensic entomology: the utility of arthropods in legal investigations. CRC Boca Raton, FL.

Catts, E. P., and N. H. Haskell. 1990. Entomology \& death-a procedural guide. Joyce's Print Shop, Inc., Clemson, SC.

Clark, K., L. Evans, and R. Wall. 2006. Growth rates of the blowfly, Lucilia sericata, on different body tissues. Forensic Sci. Int. 156: 145-149.

Clarkson, C. A., N. R. Hobischak, and G. S. Anderson. 2004. A comparison of the development rate of Protophormia terraenovae (Robineau-Desvoidy) raised under constant and fluctuating temperature regimes. Can. Soc. Forensic Sci. 37: 95-101.

Dallwitz, R. 1984. The influence of constant and fluctuating temperatures on development rate and survival of pupae of the Australian sheep blowfly Lucilia cuprina. Entomol. Exp. Appl. 36: 89-95.

Davies, L., and G. G. Ratcliffe. 1994. Development rates of some pre-adult stages in blowflies with reference to low temperatures. Med. Vet. Entomol. 8: 245-254.

Day, D. M., and J. F. Wallman. 2006. Influence of substrate tissue type on larval growth in Calliphora augur and $\mathrm{Lu}$ cilia cuprina (Diptera: Calliphoridae). J. Forensic Sci. 51: $657-663$
Fantinou, A. A., A. T. Kourti, and C. J. Saitanis. 2003. Photoperiodic and temperature effects on the intensity of larval diapause is Sesamia nonagrioides. Physiol. Entomol. 28: $82-87$.

Fantinou, A. A., D. Ch. Perdikis, and K. F. Zota. 2004. Reproductive responses to photoperiod and temperature by diapausing and nondiapausing populations of Sesamia nonagrioides Lef. (Lepidoptera-Noctuidae). Physiol. Entomol. 29: 169-175.

GraphPad Software Inc. 2003. GraphPad Prism 4. GraphPad Software Inc., San Diego, CA.

Grassberger, M., and C. Reiter. 2001. Effect of temperature on Lucilia sericata (Diptera: Calliphoridae) development with special reference to the isomegalen- and isomorphen-diagram. Forensic Sci. Int. 120: 32-36.

Grassberger, M., and C. Reiter. 2002a. Effect of temperature on development of Liopygia (=Sarcophaga) argyrstoma (Robineau-Desvoidy) (Diptera: Sarcophagidae) and its forensic implications. J. Forensic Sci. 47: 1-5.

Grassberger, M., and C. Reiter. 2002b. Effect of temperature on development of the forensically important Holarctic blow fly Protophormia terraenovae (Robineau-Desvoidy) (Diptera: Calliphoridae). Forensic Sci. Int. 128: 177-182

Grassberger, M., E. Freidrich, and C. Reiter. 2003. The blowfly Chrysomya albiceps (Wiedemann) (Diptera: Calliphoridae) as a new forensic indicator in Central Europe. Int. J. Legal Med. 117: 75-81.

Greenberg, B. 1990. Nocturnal oviposition behavior of blow flies (Diptera: Calliphoridae). J. Med. Entomol. 27: 807810.

Greenberg, B. 1991. Flies as forensic indicators. J. Med. Entomol. 28: 565-577.

Greenberg, B., and T. Tantawi. 1993. Different developmental strategies in two boreal blow flies (Diptera: Calliphoridae). J. Med. Entomol. 30: 481-484.

Harker, J. E. 1964. The physiology of diurnal rhythms. Cambridge University Press. London, United Kingdom.

Harker, J. E. 1965. The effect of photoperiod on the developmental rate of Drosophila pupae. J. Exp. Biol. 43: 411423.

Hedges, L. V., and L. Olkin. 1985. Statistical methods for meta-analysis. Academic, Orlando FL.

Huntington, T. E. 2005. Temperature-dependent development of blow flies of forensic importance and the effects on the estimation of the postmortem interval. M.S. Thesis, University of Nebraska, Lincoln, NE.

Kim, Y., and W. Song. 2000. Effect of thermoperiod and photoperiod on cold tolerance of Spodoptera exigua (Lepidoptera: Noctuidae). Environ. Entomol. 29: 868-873.

Kocarek, P. 2001. Diurnal patterns of postfeeding larval dispersal in carrion blowflies (Diptera: Calliphoridae). Eur. J. Entomol. 98: 117-119.

Lord, W. D., M. L. Goff, T. R. Adkins, and N. H. Haskell. 1994. The black soldier fly Hermetia illucens (Diptera: Stratiomyiidae) as a potential measure of human postmortem interval: Observations and case histories. J. Forensic Sci. 39: 215-222.

McWatters, H. G., and D. S. Saunders. 1998. Maternal temperature has different effects on the photoperiodic response and duration of larval diapause in blow fly ( $\mathrm{Cal}$ liphora vicina) strains collected at two latitudes. Physiol. Entomol. 23: 369-375.

Nabity, P. D. 2005. A comparison of abiotic and biotic factors on the physiological ecology of plants and insects. M.S. Thesis, University of Nebraska, Lincoln, NE.

Nabity, P. D., L. G. Higley, and T. M. Heng-Moss. 2006. Effects of temperature on development of Phormia regina 
(Diptera: Calliphoridae) and use of development data in determining time intervals in forensic entomology. J. Med. Entomol. 43: 1276-1286.

Nakamura, K. 2003. Effect of photoperiod on development and growth in a pentatomid bug, Dolycoris baccarum. Entomol. Sci. 6: 11-16.

Omkar, and S. Pathak. 2006. Effects of different photoperiods and wavelengths of light on the life-history traits of an aphidophagous ladybird, Coelophora saucia (Mulsant). J. Appl. Entomol. 130: 45-50.

Piesik, D. 2006. Effects of temperature and photoperiod on the development and survival of the dock leaf beetle (Gastroidea viridula Deg.) Electronic J. Polish Agric. Univ. 9(2): 27.

Pittendrigh, C. S. 1967. Circadian systems I. The driving oscillation and its assay in Drosophila pseudoobscura. Proc. Natl. Acad. Sci. 58: 1762-1767.

Pittendrigh, C. S., and S. D. Skopik. 1970. Circadian systems, $\mathrm{V}$. the driving oscillation and the temporal sequence of development. Proc. Natl. Acad. Sci. 65: 500-507.

Roach, S. H., and P. L. Adkisson. 1970. Role of photoperiod and temperature in the induction of pupal diapause in the bollworm Heliothis zea. J. Insect Physiol. 16: 1591-1597.

SAS Institute. 2002. PROC user's manual, version 9.1. SAS Institute, Cary, NC.
Saunders, D. S. 1972. Circadian control of larval growth rate in Sarcophaga argyrostoma. Proc. Natl. Acad. Sci. 69: $2738-2740$

Schwartz, W. J. 2004. Sunrise and sunset in fly brains. Nature (Lond.) 431: 751-752.

Singh, D., and M. Bharti. 2001. Further observations on the nocturnal oviposition behaviour of blow flies (Diptera: Calliphoridae). Forensic Sci. Int. 120: 124-126.

Skopik, S. D., and C. S. Pittendrigh. 1967. Circadian systems, II. The oscillation in the individual Drosophila pupa: its independence of developmental stage. Proc. Natl. Acad. Sci. 58: 1862-1869.

Spencer, J. 2002. The nocturnal oviposition behavior of blowflies in the southwest of Britain during the months of August and September. M.S./PGDip, Bournemouth University Poole, Dorset, United Kingdom.

Tachibana, S., and H. Numata. 2004. Parental and direct effects of photoperiod and temperature on the induction of larval diapause in the blow fly Lucilia sericata. Physiol. Entomol. 29: 39-44.

Tessmer, J. W., C. L. Meek, V. L. Wright. 1995. Circadian patterns of oviposition by necrophilous flies (Diptera: Calliphoridae) in southern Louisiana. Southwest. Entomol. 20: 439-445.

Received 12 May 2006; accepted 9 October 2006. 